\title{
Intra- and Intermolecular Steric Hindrance Effects Induced Higher Open-Circuit Voltage and Power Conversion Efficiency
}

\author{
Liangliang Han, ${ }^{\dagger}$ Weichao Chen, ${ }^{\dagger}$ Tong Hu, Junzhen Ren, ${ }^{\dagger}$ Meng Qiu, ${ }^{\dagger}$ Yuanhang Zhou, ${ }^{\dagger}$
} Dangqiang Zhu, ${ }^{\dagger}$ Ning Wang, ${ }^{\dagger}$ Mingliang Sun, ${ }^{\dagger}$ and Renqiang Yang ${ }^{*}, \S^{\dagger}$

${ }^{\dagger}$ CAS Key Laboratory of Bio-based Materials, Qingdao Institute of Bioenergy and Bioprocess Technology, Chinese Academy of Sciences, Qingdao 266101, China

${ }^{\ddagger}$ Institute of Material Science and Engineering, Ocean University of China, Qingdao 266100, China

${ }^{\S}$ State Key Laboratory of Luminescent Materials and Devices, South China University of Technology, Guangzhou 510641, China

Supporting Information

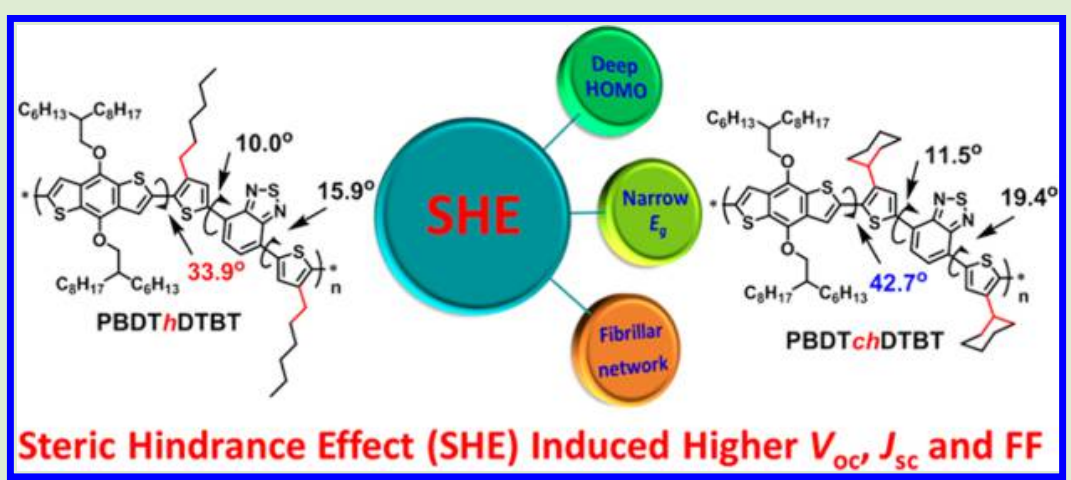

ABSTRACT: A pair of donor-acceptor polymers PBDThDTBT and PBDTchDTBT are synthesized, which share the same conjugated backbone, but are designed with hexyl and cyclohexyl side chains, respectively. The stronger steric hindrance of cyclohexyl endows PBDTchDTBT a deeper lying HOMO energy level of $-5.39 \mathrm{eV}$ compared to $-5.22 \mathrm{eV}$ for PBDThDTBT. However, PBDThDTBT and PBDTchDTBT exhibit a similar optical bandgap around $1.72 \mathrm{eV}$ and a hole mobility around $10^{-5}$ $\mathrm{cm}^{2} \mathrm{~V}^{-1} \mathrm{~s}^{-1}$. Interestingly, the PBDT chDTBT/PC $\mathrm{PB}_{71}$ BM blends exhibited higher hole mobility than PBDThDTBT/PC $\mathrm{BM}_{71} \mathrm{Bfter}$ DIO was added. The higher hole mobility and fibrillar network in the active layer endows PBDTchDTBT higher power conversion efficiency of $7.9 \%$, together with simultaneously improved open-circuit voltage of $0.80 \mathrm{~V}$, short-circuit current density of $13.50 \mathrm{~mA} \mathrm{~cm}{ }^{-2}$, and fill factor of $72.74 \%$ after a systemic study of their solar cell devices.

S emiconducting polymer is considered as the ideal material for next generation large area optoelectronics application in virtue of its superior solution processing and film forming ability. $^{1-5}$ When a semiconducting polymer is employed, research is mainly focused on its frontier molecular orbital energy levels and optical and optoelectronic characteristics, which have reliance on the polymer's planarity, interchain aggregation, alkyl substituents, and molecular weight. ${ }^{6-9}$ One simple and effective strategy employed to adjust the energy levels and optical property of a semiconducting polymer is intra- or intermolecular steric hindrance effect (SHE). ${ }^{10-13}$ However, SHE has been reported with negative effect on molecular self-organization in the donor-acceptor (D-A) oligmers. ${ }^{14}$ Intermolecular SHE introduced to the polymer backbone could prevent molecular packing and then result in weaker crystallinity. ${ }^{15}$ Intramolecular SHE may reduce the $\pi$ orbital overlap between two adjacent units and lead to undesirable hypochromatic shifted absorption spectra and wide bandgap $\left(E_{\mathrm{g}}\right),{ }^{10,16-20}$ however, as is well-known, wide absorption spectra, and narrow $E_{\mathrm{g}}$ of the absorber are crucial for organic solar cells (OSCs) application. ${ }^{21}$

Although SHE has been considered as a negative effect for polymer's self-aggregation and effective conjugation, one advantage should be pointed out, that is, SHE can significantly decrease the highest occupied molecular orbital (HOMO) energy levels of the polymer. For example, poly(3-cyclohexylthiophene) ( $\mathrm{P} 3 \mathrm{ch} \mathrm{T})$ exhibited more twisted conjugating backbone than poly(3-hexylthiophene) (P3hT) because of stronger SHE of cyclohexyl than hexyl, which resulted in a larger dihedral angle $(\theta)$ between the two adjacent thiophene rings together with a wider $E_{\mathrm{g}}$ and a deeper lying $\mathrm{HOMO}$ of $-5.72 \mathrm{eV}, 0.72 \mathrm{eV}$ lower than that of P3hT $(-5.0 \mathrm{eV})$ experimentally. ${ }^{10}$ Theoretically, Brédas and co-workers reported that the ionic potential of the polythiophene increased gradually as the torsion angle increased from 0 to $90^{\circ} .^{22}$ This

Received: January 23, 2015

Accepted: March 12, 2015

Published: March 13, 2015 
will be very interesting for OSCs application, which is composed of a polymeric donor and a fullerene acceptor, and the deeper lying HOMO of the polymer donor will be beneficial for higher open-circuit voltage $\left(V_{\text {oc }}\right){ }^{23}$ Several examples have been reported employing SHE (alkyl side chains) to design deeper HOMO polythiophenes with improved $V_{\mathrm{oc}}$ in their OSCs, unfortunately, $E_{\mathrm{g}}$ of the polymers became wider together with decreased hole mobility $\left(\mu_{\text {hole }}\right)$, which resulted in lower short-circuit current density $\left(J_{\text {sc }}\right)$, fill factor (FF), and inconspicuous improvement of power conversion efficiency (PCE) compared to P3hT. ${ }^{24}$ Furthermore, lower $J_{s c}, \mathrm{FF}$, and extremely low $\mu_{\text {hole }}$ were also obtained when SHE was employed to design an indacenodithiophenebased polymer for OSCs application. ${ }^{25}$ Thus, it can be seen, employing simple SHE to design semiconducting polymer for highly efficient OSCs will be a challenging issue. A comprehensive survey of the chemical methods for designing high PCE polymers found that the inductive effect such as introducing fluorine or sulfur atoms to the polymer backbone has been considered as one of the most effective and successful methods, which can bring about simultaneous improvement of $V_{\text {oc }} J_{\text {sc }}$ and FF on their OSCs devices. ${ }^{26-30}$ However, chemically introducing fluorine ${ }^{31}$ or sulfur ${ }^{32}$ always makes the synthetic route more complicated and expensive, and fluorine atoms sometimes reduce the solubility of the polymers remarkably. ${ }^{33}$

In this communication, we reported two $\mathrm{D}-\mathrm{A}$ polymers incorporating 4,8-bis(hexyldecyloxy)benzo[1,2-b:4,5- $\left.b^{\prime}\right]$ dithiophene (alkoxy-BDT) as the donor unit and either 4,7bis(4-hexylthiophen-2-yl)benzo[c] $[1,2,5]$ thiadiazole ( $h$ DTBT) or 4,7-bis (4-cyclohexylthiophen-2-yl)benzo[c] [1,2,5]thiadiazole (chDTBT) as the acceptor unit (Scheme 1). As

Scheme 1. Synthesis of PBDThDTBT and PBDTchDTBT

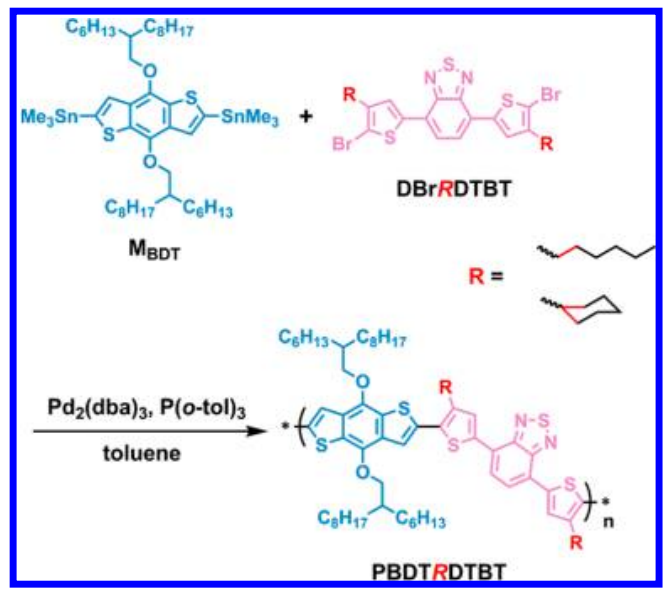

shown in Scheme 1, analogous hexyl and cyclohexyl were chosen as side chains because they have the same carbon number and similar electronic effect except they were connected to the polymer backbone with a primary carbon and a secondary carbon, respectively. PBDTchDTBT exhibited a deeper lying HOMO of $-5.39 \mathrm{eV}$ compared to $-5.22 \mathrm{eV}$ for PBDThDTBT. Interestingly, the two polymers had almost the same $E_{\mathrm{g}}$. In their OSC devices, PBDTchDTBT exhibited higher $V_{\mathrm{oc}} J_{\mathrm{sc}}$ and FF than PBDThDTBT, giving rise to a PCE value up to $7.9 \%$, which was much higher than that of PBDThDTBT (5.9\%). These obvious improvements were ascribed to a deeper lying $\mathrm{HOMO}$ of PBDTchDTBT together with a tunable fine nanoscale fibrillar network in PBDTchDTBT/[6,6]-phenyl $\mathrm{C}_{71}$ butyric acid methyl-ester $\left(\mathrm{PC}_{71} \mathrm{BM}\right)$ blend. To our knowledge now, SHE is first designed with simultaneously improved $V_{\mathrm{oc}}$ $J_{\text {sc }}$ and FF for OSCs application, and $7.9 \%$ is the highest PCE among alkoxy-BDT and DTBT copolymers. ${ }^{34}$

4,7-Bis (5-bromo-4-hexylthiophen-2-yl)benzo[c] [1,2,5]thiadiazole (DBrhDTBT) ${ }^{35}$ and 2,6-bis(trimethyltin)-4,8-bis(hexyldecyloxy)benzo[1,2- $\left.b: 4,5-b^{\prime}\right]$ dithiophene $\left(M_{\mathrm{BDT}}\right)^{36}$ were synthesized according to the literature methods. The cyclohexyl substituted monomer 4,7-bis(5-bromo-4-cyclohexylthiophen-2yl)benzo $[c][1,2,5]$ thiadiazole (DBrchDTBT) was first reported here with similar synthetic route of DBrhDTBT (Scheme S1). The final copolymers PBDThDTBT and PBDTchDTBT were prepared via Stille coupling polymerization. PBDThDTBT and PBDTchDTBT show excellent solubility in halogenated solvents and high number-average molecular weight $\left(M_{n}\right)$ of $57.2 \mathrm{~kg} \mathrm{~mol}^{-1}$ and $38.8 \mathrm{~kg} \mathrm{~mol}^{-1}$ with polydispersity index (PDI) of 2.4 and 2.0, respectively. The relative lower $M_{n}$ of PBDTchDTBT compared to PBDThDTBT may be because of the stronger SHE of cyclohexyl than hexyl, which made the Stille coupling copolymerization more difficult. However, the relatively high molecular weights of $\mathrm{PBDThDTBT}$ and $\mathrm{PBDT}$ chDTBT indicated an efficient polymerization reaction occurred. PBDThDTBT and PBDTchDTBT exhibited nearly indistinguishable decomposition temperature $\left(T_{\mathrm{d}}\right)$ with $5 \%$ weight loss denoted at $\sim 318{ }^{\circ} \mathrm{C}$ (Figure S1).

The onset oxidation potential of PBDThDTBT was estimated at about $0.82 \mathrm{~V}$ (Figure S2), and the HOMO was calculated to be $-5.22 \mathrm{eV}$ relative to ferrocene as an internal standard. Interestingly, because of the SHE of cyclohexyl side chain, PBDTchDTBT exhibited a higher oxidation potential with an onset at $0.99 \mathrm{~V}$, a deeper HOMO of $-5.39 \mathrm{eV}$ was derived. The dihedral angles in the repeated BDThDTBT and BDTchDTBT units were optimized with the density functional theory (DFT) method under B3LYP/6-31G(d,p) level. ${ }^{37}$ As shown in Figure S3, PBDTchDTBT exhibited a larger $\theta 1=$ $42.7^{\circ}$ compared to $\theta 1=33.9^{\circ}$ of PBDThDTBT. The larger $\theta 1$ of PBDTchDTBT showed us clearly stronger intramolecular SHE of cyclohexyl than hexyl which could reduce the $\pi$-orbital overlap between BDT and adjacent thiophene rings and result in a deeper lying HOMO.

In dilute solutions, as shown in Figure 1, PBDThDTBT and PBDTchDTBT exhibited almost unanimous intramolecular CT transition absorption ${ }^{38}$ centered at $\sim 595 \mathrm{~nm}$, indicating that although cyclohexyl could result in larger $\theta 1$, however, such

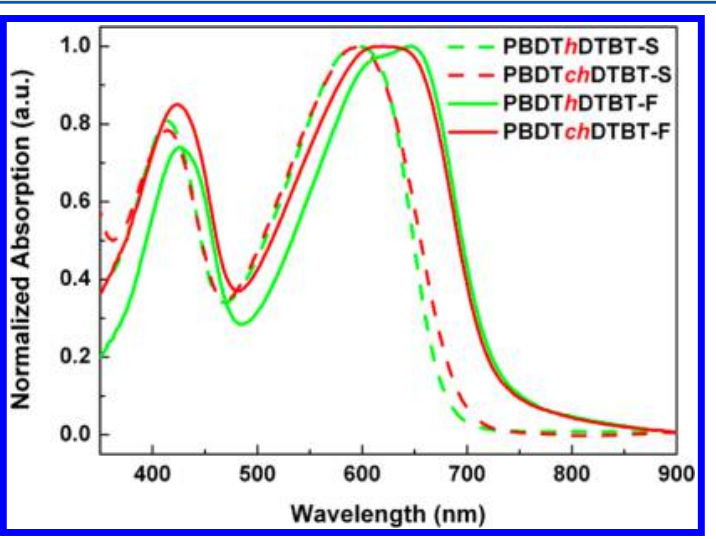

Figure 1. UV-vis absorption spectra of PBDThDTBT and PBDTchDTBT in chloroform solutions (S) and neat films (F). 
intramolecular SHE can negligibly affect the CT transition state. In their solid state films, PBDTchDTBT exhibited slightly blue-shifted peak wavelength $\left(\lambda_{\max }=616 \mathrm{~nm}\right)$. The reason may be that cyclohexyl reduced the intermolecular aggregation of the polymer because of its stronger intermolecular SHE. However, there was nearly no change of the absorption edge $\left(\lambda_{\text {edge }}\right)$ for PBDTchDTBT compared to PBDThDTBT, and, interestingly, PBDTchDTBT exhibited wider absorption spectra with full width at half maximum estimated to be 170 $\mathrm{nm}$ in the CT transition band, $10 \mathrm{~nm}$ wider than that of PBDThDTBT. The optical $E_{\mathrm{g}}$ of PBDThDTBT and PBDTchDTBT were estimated to be 1.71 and $1.72 \mathrm{eV}$, respectively, indicating efficient $\mathrm{CT}$ transition states and interchain aggregation existed in both the polymers although sterically hindered cyclohexyl was introduced in PBDTchDTBT. The lowest unoccupied molecular orbitals (LUMOs) of PBDThDTBT and PBDTchDTBT were calculated as -3.51 and $-3.67 \mathrm{eV}$, respectively. Both the HOMO and LUMO of PBDTchDTBT down-shifted, while the $E_{\mathrm{g}}$ of the two polymers were almost identical. However, the cyclohexyl will destroy the $\pi-\pi$ conjugation for P3chT by reducing the $\pi$ orbital overlap along the whole backbone and resulting in wider $E_{\mathrm{g} .}{ }^{10}$

Both the polymers have three dihedral angles per repeat unit as depicted in Figure 2 and simulated in Figure S3. Obviously,

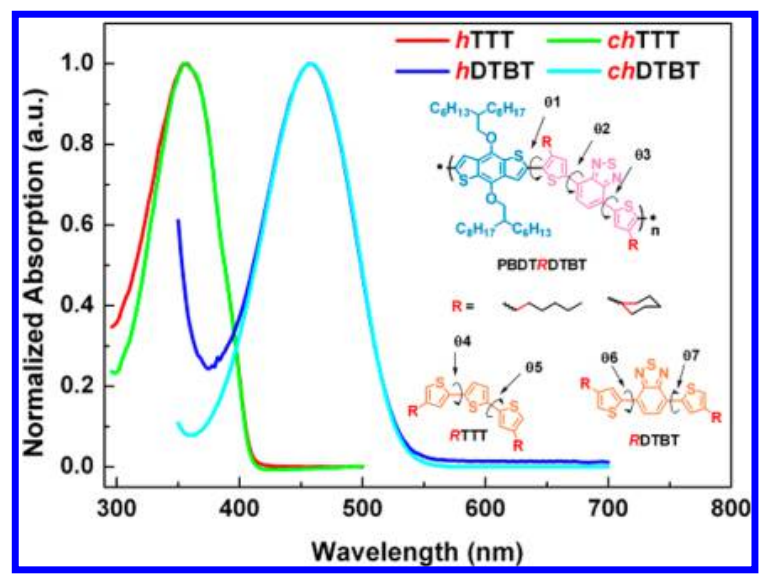

Figure 2. UV-vis absorption spectra of RTTT and RDTBT in hexane solutions (Inset: molecular structures and dihedral angles existed in the $\mathrm{D}-\mathrm{A}$ polymers PBDTRDTBT, $\pi-\pi$ conjugating oligmers $R T T T$, $\mathrm{D}-\mathrm{A}$ type molecules RDTBT).

larger $\theta 1$ can significantly influence the effective conjugation between BDT and thiophenes and resulted in a deeper lying HOMO. However, the wide absorption of these $\mathrm{D}-\mathrm{A}$ polymers was originated from the CT transition state between the electron donating group and electron withdrawing unit. Here, benzo $[c][1,2,5]$ thiadiazole $(\mathrm{BT})$ unit plays the role of electron acceptor; therefore, effective conjugation is indispensable between BT and flanking thiophene rings. $\theta 2$ and $\theta 3$ usually determine whether effective conjugation and CT transition states exist in the DTBT system. ${ }^{39}$ In order to elucidate how the substituents could affect $\theta 2$ and $\theta 3$ in the $\mathrm{D}-\mathrm{A}$ polymers, we designed two $\pi-\pi$ conjugating small molecules $2,5-\mathrm{bis}\left(4^{\prime}\right.$ hexyl-2'-thienyl)thiophene ( $h$ TTT) and 2,5-bis ( $4^{\prime}$-cyclohexyl$2^{\prime}$-thienyl)thiophene (chTTT); in addition, D-A-type oligmers $h \mathrm{DTBT}$ and chDTBT were also included (Figure 2, inset). In the oligomer thiophene systems, their absorption originated from the $\pi-\pi$ conjugation was very sensitive to the twisted angle of the adjacent thiophenes. ${ }^{40}$ Two dihedral angles $\theta 4$ and $\theta 5$ existed in $h \mathrm{TTT}$ or chTTT, and their absorption spectra (Figure 2, hexane solutions) were almost identical with the same $\lambda_{\max }=355 \mathrm{~nm}$ and $\lambda_{\text {edge }}=410 \mathrm{~nm}$, which indicated effective $\pi$-orbital overlap between adjacent thiophene rings both in $h \mathrm{TTT}$ and chTTT, and the 4-position substituents can hardly influence $\theta 4$ and $\theta 5$. In the $\mathrm{D}-\mathrm{A}$ system, same phenomena were observed, and efficient CT transition between thiophene and BT occurred regardless of the 4-positions were substituted with hexyl or sterically hindered cyclohexyl. From which we infer PBDThDTBT and PBDTchDTBT possess similar $\theta 2$ and $\theta 3$, respectively, which warrants effective CT transition in both the polymers. The simulated results also show us a little differences between the two dihedral angles $\left(\Delta \theta 2=1.5^{\circ}\right.$ and $\Delta \theta 3=3.5^{\circ}$, Figure S3). This can help to explain why PBDThDTBT and PBDTchDTBT exhibited similar CT transition absorption in their dilute solutions. And the slightly blue-shifted $\lambda_{\max }$ for PBDTchDTBT in the film state was the result of intermolecular SHE of cyclohexyl and such steric hindrance showed negligible effects of the polymer $E_{\mathrm{g}}$. It should be pointed out that the electrochemical and optical differences of PBDTchDTBT compared to PBDThDTBT were mainly induced by SHE because the electronic effects of nonchromophoric cyclohexyl and hexyl can be eliminated compared to some conjugated side chains. ${ }^{41}$ This will be an encouraging strategy to design $\mathrm{D}-\mathrm{A}$ polymers in conformity with the "weak donor-strong acceptor" ideology. ${ }^{42}$

Solar cells were fabricated with a conventional device structure ITO/PEDOT:PSS/polymer: $\mathrm{PC}_{71} \mathrm{BM} / \mathrm{Ca} / \mathrm{Al}$ and measured under the illumination of AM $1.5 \mathrm{G}(100 \mathrm{~mW}$ $\left.\mathrm{cm}^{-2}\right) .^{43}$ Initially, different donor/acceptor ratios (1:1, $1: 1.5$, $1: 2$, and $1: 2.5)$ were examined to find the optimum weight ratio (Figure S4). At a ratio of $1: 1$, a high $V_{\text {oc }}$ of $0.84 \mathrm{~V}$ was obtained for PBDTchDTBT and $0.07 \mathrm{~V}$ higher than that of PBDThDTBT, which was even higher than the alkoxy-BDT and fluorinated DTBT incorporated polymer. ${ }^{44}$ As $\mathrm{PC}_{71} \mathrm{BM}$ amount increased, all the devices of PBDTchDTBT exhibited higher $V_{\text {oc }}$ than PBDThDTBT at specific polymer/PC $\mathrm{P}_{71} \mathrm{BM}$ ratios (Table S1 and Figure S5). 1,8-Diiodooctane (DIO) was used as the additive to optimize the morphology of the polymer/PC $\mathrm{PC}_{71} \mathrm{BM}$ blends. ${ }^{45,46}$ In the PBDThDTBT/PC ${ }_{71} \mathrm{BM}$ blend, DIO was added with volume fraction of $1,1.5$, and $2 \%$, unfortunately, the PCE declined gradually as the DIO volume fraction increased (Figure S6 and Table S2). For PBDTchDTBT/PC ${ }_{71}$ BM blend, when $1 \%$ DIO was added, the $J_{\mathrm{sc}}$ was improved significantly to $12.27 \mathrm{~mA} \mathrm{~cm}{ }^{-2}$, which resulted in a higher PCE of $6.6 \%$. When $3 \%$ DIO was added, a higher $J_{\mathrm{sc}}$ of $13.50 \mathrm{~mA} \mathrm{~cm}{ }^{-2}$ was obtained and the FF improved to $72.74 \%$, highly efficient OSCs with PCE $=7.9 \%$ was realized (Figure $3 \mathrm{a}$ and Table 1). The EQE spectra of PBDTchDTBT was higher than PBDThDTBT in the whole response wavelength from $300-750 \mathrm{~nm}$, as shown in Figure 3b, resulting in higher $J_{\mathrm{sc}}$ of the device based on PBDTchDTBT than PBDThDTBT. The $J_{\mathrm{sc}}$ values $\left(10.55 \mathrm{~mA} \mathrm{~cm}^{-2}\right.$ for PBDThDTBT and $13.48 \mathrm{~mA} \mathrm{~cm} \mathrm{~cm}^{-2}$ for PBDTchDTBT) calculated from the integration of the EQE spectra agreed well with the $J_{s c}$ values recorded from the $J-V$ measurements.

The only difference of PBDThDTBT and PBDTchDTBT structurally was the nonchromophoric alkyl chains, besides which, both the polymers shared the same conjugating backbone together with comparative $E_{\mathrm{g}}$ and $\mu_{\text {hole }}$ of $1.23 \times$ $10^{-5} \mathrm{~cm}^{2} \mathrm{~V}^{-1} \mathrm{~s}^{-1}$ and $1.07 \times 10^{-5} \mathrm{~cm}^{2} \mathrm{~V}^{-1} \mathrm{~s}^{-1}$, respectively, measured using space-charge-limited-current (SCLC) model 


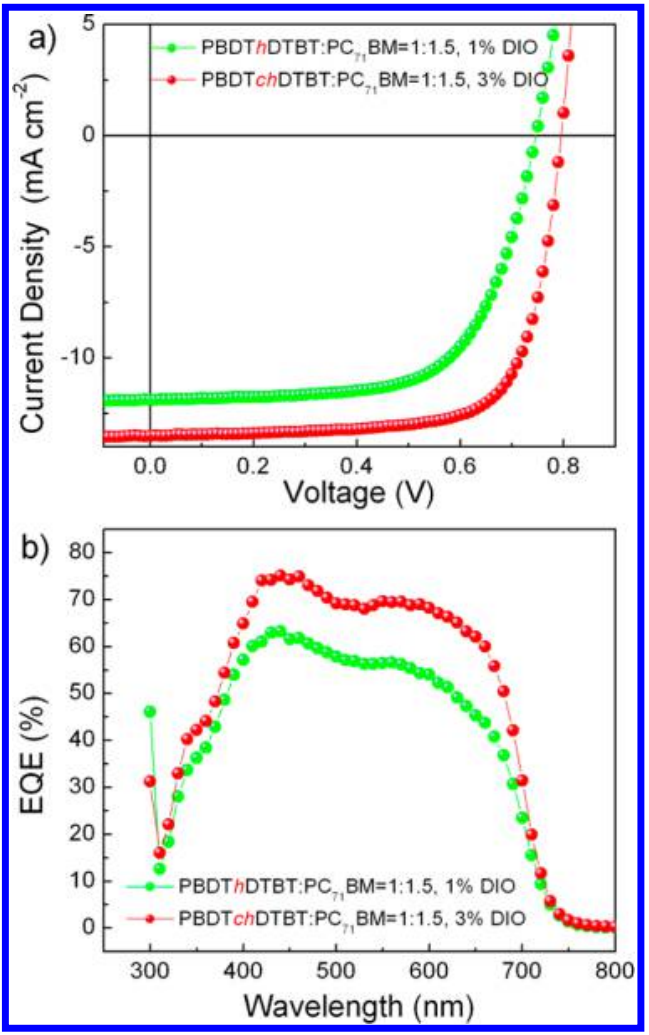

Figure 3. $J-V$ (a) and EQE (b) curves of the devices based on PBDThDTBT and PBDTchDTBT.

Table 1. Device Parameters of PBDThDTBT $/ \mathrm{PC}_{71} \mathrm{BM}=$ 1:1.5 with $1 \%$ DIO and PBDTchDTBT $/ \mathrm{PC}_{71} \mathrm{BM}=1: 1.5$ with 3\% DIO ( $h$ : PBDThDTBT; $c h$ : PBDTchDTBT)

$\begin{array}{ccccc}\text { entry } & V_{\mathrm{oc}}(\mathrm{V}) & J_{\mathrm{sc}}\left(\mathrm{mA} \mathrm{cm}{ }^{-2}\right) & \mathrm{FF}(\%) & \mathrm{PCE}^{a}(\%) \\ h & 0.75 & 11.60 & 68.22 & 5.9(5.8) \\ c h & 0.80 & 13.50 & 72.74 & 7.9(7.7) \\ & \\ & \\ & \end{array}$

(Figure S7). In order to better explain their different photovoltaic properties, atom force microscopy (AFM), and bright field transmission electron microscopy (TEM) were used to explore their morphology and phase separation characteristics. Both PBDThDTBT and PBDTchDTBT exhibited good film-forming ability with root-mean-square (RMS) surface roughness $<3 \mathrm{~nm}$ in their neat films (Figure S8). Smooth films can also be observed from the AFM height images of polymer $/ \mathrm{PC}_{71} \mathrm{BM}$ blends, as shown in Figure $4 \mathrm{a}-1, \mathrm{~b}-1, \mathrm{c}-1, \mathrm{~d}-1$. However, serious phase separation can be observed from the phase images given from AFM phase (Figure 4a-2) and TEM (Figure 4a-3) images in PBDThDTBT/PC ${ }_{71} \mathrm{BM}$ blends. Some $\mathrm{PC}_{71} \mathrm{BM}$ aggregated even $\sim 100 \mathrm{~nm}$ in size, which would diminish exciton migration to the donor/acceptor interface and is not favorable for charge separation. ${ }^{47}$ When DIO was added, there was no obvious improvement about the phase separation, as shown in Figure 4b-2,b-3, and obvious $\mathrm{PC}_{71} \mathrm{BM}$ aggregations can still be observed, which resulted in nearly no improvements about the $J_{\text {sc }}$ and the FF dropped from $69.78 \%$ to $68.22 \%$. As shown in Figure 4c-2,c-3, fibril-like polymer aggregations $\sim 25$ $\mathrm{nm}$ in width were observed for PBDT $c h D T B T / \mathrm{PC}_{71} \mathrm{BM}$ blends without DIO. ${ }^{48}$ However, typical exciton diffusion lengths for conjugated polymers are a few nanometers, and hence, the wider fibrils may affect the percentage of excitons that reach the

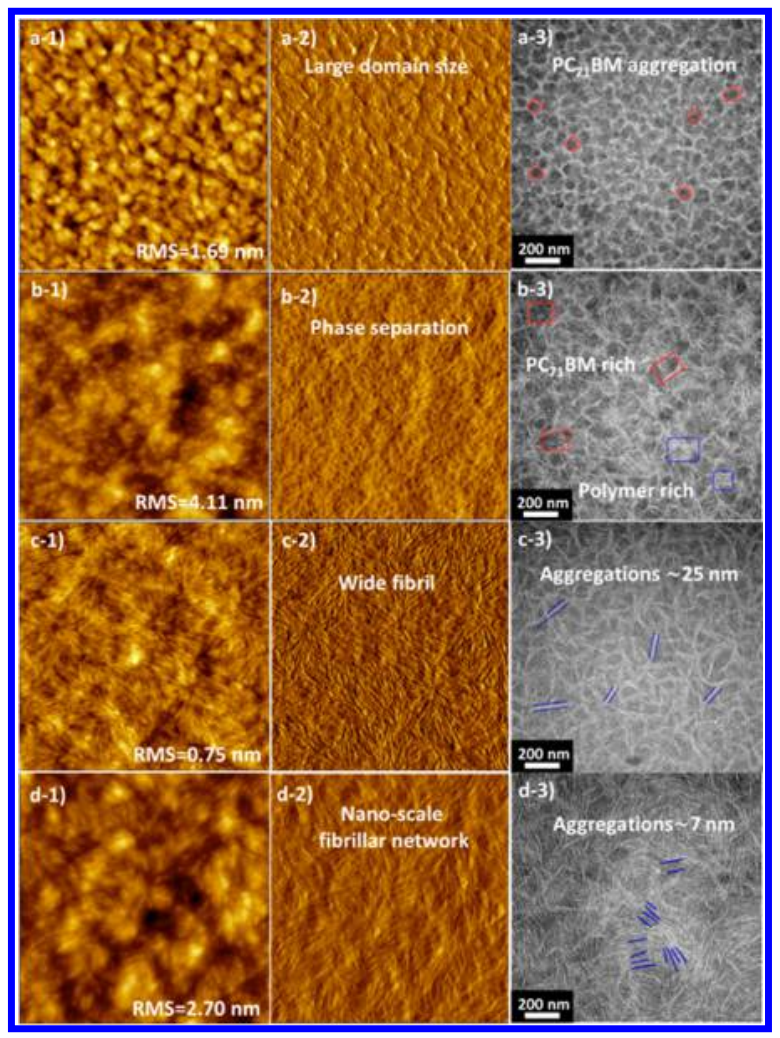

Figure 4. AFM height $(2 \times 2 \mu \mathrm{m}, \mathrm{a}-1, \mathrm{~b}-1, \mathrm{c}-1, \mathrm{~d}-1)$, phase (a-2, b-2, c$2, \mathrm{~d}-2)$, and TEM (a-3, b-3, c-3, d-3) images of the active layers containing PBDThDTBT/PC ${ }_{71} \mathrm{BM}(\mathrm{a}), \mathrm{PBDT} h \mathrm{DTBT} / \mathrm{PC}_{71} \mathrm{BM}$ with $1 \%$ DIO (b), PBDTchDTBT/PC ${ }_{71} \mathrm{BM}$ (c), and PBDTchDTBT/ $\mathrm{PC}_{71} \mathrm{BM}$ with $3 \%$ DIO (d).

interface with the fullerene where charge generation occurs. ${ }^{49}$ Therefore, relative low $J_{\mathrm{sc}}$ of $10.24 \mathrm{~mA} \mathrm{~cm}^{-2}$ and PCE of $5.7 \%$ were obtained for $\mathrm{PBDT}$ chDTBT/PC ${ }_{71} \mathrm{BM}$ device without DIO. Interestingly, the fibril width was remarkably reduced to $\sim 7 \mathrm{~nm}$ (Figure 4d-2,d-3) after 3\% DIO was added, and a nanoscale fibrillar network was observed, which is desired for better charge transfer according to Janssen's work, ${ }^{50}$ and led to improvement of FF from $66.47 \%$ to $72.74 \%$. The narrow fibril of the polymer is also beneficial for exciton diffusion to the PBDT chDTBT $/ \mathrm{PC}_{71} \mathrm{BM}$ interface then higher $J_{\mathrm{sc}}=13.50 \mathrm{~mA}$ $\mathrm{cm}^{-2}$ was achieved. ${ }^{50}$ Interestingly, the $\mu_{\text {hole }}$ of PBDThDTBT/ $\mathrm{PC}_{71} \mathrm{BM}$ declined from $3.08 \times 10^{-5} \mathrm{~cm}^{2} \mathrm{~V}^{-1} \mathrm{~s}^{-1}$ to $2.18 \times 10^{-5}$ $\mathrm{cm}^{2} \mathrm{~V}^{-1} \mathrm{~s}^{-1}$ when $1 \%$ DIO was added, however, the $\mu_{\text {hole }}$ of PBDTchDTBT/PC ${ }_{71} \mathrm{BM}$ increased from $1.62 \times 10^{-5} \mathrm{~cm}^{2} \mathrm{~V}^{-1}$ $\mathrm{s}^{-1}$ to $3.46 \times 10^{-5} \mathrm{~cm}^{2} \mathrm{~V}^{-1} \mathrm{~s}^{-1}$ as $3 \%$ DIO was added (Figure S9). This regular pattern aggreed with the morphology and phase separation changing in both the polymer $/ \mathrm{PC}_{71} \mathrm{BM}$ blends before and after DIO was added. Higher $\mu_{\text {hole }}$ is also beneficial for higher $J_{\mathrm{sc}}$ and FF. ${ }^{51,52}$

In conclusion, a reasonable conception of steric hindrance affecting $\mathrm{D}-\mathrm{A}$ polymer's photophysical, electrochemical and photovoltaic characteristics is realized by a parallel comparison of hexyl and cyclohexyl substituted PBDTDTBTs. Our study indicates that the well designed steric hindrance can decrease both the HOMO and LUMO energy levels of the PBDTDTBTs but cannot influence their $E_{\mathrm{g}}$, which is very important for designing high efficiency OSC materials. Replacing hexyl by cyclohexyl results in higher $V_{\text {oo }} J_{\text {so }}$ and FF, and finally, highest PCE $=7.9 \%$ is realized in their OSCs devices. 


\section{ASSOCIATED CONTENT}

\section{S Supporting Information}

Experimental details on materials and methods, synthesis of monomers and polymers, thermal stability, hole mobility measurements, theoretical calculation, and device fabrication. This material is available free of charge via the Internet at http://pubs.acs.org.

\section{AUTHOR INFORMATION}

\section{Corresponding Author}

*E-mail: yangrq@qibebt.ac.cn.

Notes

The authors declare no competing financial interest.

\section{ACKNOWLEDGMENTS}

This work was supported by the Ministry of Science and Technology of China (2014CB643501, 2010DFA52310), the National Natural Science Foundation of China (21204097, 21274161, 51173199, and 61405209), and the Chinese Academy of Sciences (KGCX2-YW-399+9-2).

\section{REFERENCES}

(1) Burroughes, J. H.; Bradley, D. D. C.; Brown, A. R.; Marks, R. N.; Mackay, K.; Friend, R. H.; Burns, P. L.; Holmes, A. B. Nature 1990, 347, 539-541.

(2) Yu, G.; Gao, J.; Hummelen, J. C.; Wudl, F.; Heeger, A. J. Science 1995, 270, 1789-1790.

(3) Leclerc, M.; Morin, J. F. Design and Synthesis of Conjugated Polymers; John Wiley and Sons: New York, 2010.

(4) Günes, S.; Neugebauer, H.; Sariciftci, N. S. Chem. Rev. 2007, 107, 1324-1338.

(5) Thompson, B. C.; Fréchet, J. M. J. Angew. Chem., Int. Ed. 2008, 47, 58-77.

(6) Mei, J. G.; Bao, Z. N. Chem. Mater. 2013, 26, 604-615.

(7) Kline, R. J.; McGehee, M. D.; Kadnikova, E. N.; Liu, J. S.; Fréchet, J. M. J. Adv. Mater. 2003, 15, 1519-1522.

(8) Lei, T.; Wang, J. Y.; Pei, J. Acc. Chem. Res. 2014, 47, 1117-1126.

(9) Peet, J.; Heeger, A. J.; Bazan, G. C. Acc. Chem. Res. 2009, 42, $1700-1708$.

(10) Andersson, M. R.; Berggren, M.; Inganäs, O.; Gustafsson, G.; Gustafsson-Carlberg, J. C.; Selse, D.; Hjertberg, T.; Wennerström, O. Macromolecules 1995, 28, 7525-7529.

(11) Cheng, Y. J.; Yang, S. H.; Hsu, C. S. Chem. Rev. 2009, 109, $5868-5923$.

(12) Zhou, H. X.; Yang, L. Q.; You, W. Macromolecules 2012, 45, 607-632.

(13) Wang, Y. Y.; Heck, B.; Schiefer, D.; Agumba, J. O.; Sommer, M.; Wen, T.; Reiter, G. ACS Macro Lett. 2014, 3, 881-885.

(14) Melucci, M.; Favaretto, L.; Zanelli, A.; Cavallini, M.; Bongini, A.; Maccagnani, P.; Ostoja, P.; Derue, G.; Lazzaroni, R.; Barbarella, G. Adv. Funct. Mater. 2010, 20, 445-452.

(15) Ko, S. W.; Verploegen, E.; Hong, S. H.; Mondal, R.; Hoke, E. T.; Toney, M. F.; McGehee, M. D.; Bao, Z. N. J. Am. Chem. Soc. 2011, 133, 16722-16725.

(16) Berggren, M.; Inganäs, O.; Gustafsson, G.; Rasmusson, J.; Andersson, M. R.; Hjertberg, T.; Wennerström, O. Nature 1994, 372, 444-446.

(17) Berggren, M.; Gustafsson, G.; Inganäs, O.; Andersson, M. R.; Wennerström, O.; Hjertberg, T. Adv. Mater. 1994, 6, 488-490.

(18) Kraft, A.; Grimsdale, A. C.; Holmes, A. B. Angew. Chem., Int. Ed. 1998, 37, 402-428.

(19) Pei, J.; Yu, W. L.; Huang, W.; Heeger, A. Acta Polym. 1999, 50, 327-331.

(20) Pei, J.; Yu, W. L.; Huang, W.; Heeger, A. J. Macromolecules 2000, 33, 2462-2471.

(21) Heeger, A. J. Adv. Mater. 2014, 26, 10-28.
(22) Themans, B.; Salaneck, W. R.; Brédas, J. L. Synth. Met. 1989, 28, 359-364.

(23) Dennler, G.; Scharber, M. C.; Ameri, T.; Denk, P.; Forberich, K.; Waldauf, C.; Brabec, C. J. Adv. Mater. 2008, 20, 579-583.

(24) Ko, S. W.; Hoke, E. T.; Pandey, L.; Hong, S. H.; Mondal, R.; Risko, C.; Yi, Y. P.; Noriega, R.; McGehee, M. D.; Brédas, J. L.; Salleo, A.; Bao, Z. N. J. Am. Chem. Soc. 2012, 134, 5222-5232.

(25) Chen, C. P.; Hsu, H. L. Macromol. Rapid Commun. 2013, 34, $1623-1628$.

(26) Liang, Y. Y.; Xu, Z.; Xia, J. B.; Tsai, S. T.; Wu, Y.; Li, G.; Ray, C.; Yu, L. P. Adv. Mater. 2010, 22, E135-E138.

(27) Zhou, H. X.; Yang, L. Q.; Stuart, A. C.; Price, S. C.; Liu, S. B.; You, W. Angew. Chem., Int. Ed. 2011, 50, 2995-2998.

(28) Lee, D. Y.; Hubijar, E.; Kalaw, G. J. D.; Ferraris, J. P. Chem. Mater. 2012, 24, 2534-2540.

(29) Nguyen, T. L.; Choi, H. S.; Ko, S. J.; Uddin, M. A.; Walker, B.; Yum, S. J.; Jeong, J. E.; Yun, M. H.; Shin, T. J.; Hwang, S. G. Energy Environ. Sci. 2014, 7, 3040-3051.

(30) Cui, C. H.; Wong, W. Y.; Li, Y. F. Energy Environ. Sci. 2014, 7, 2276-2284.

(31) Zhang, Y.; Chien, S. C.; Chen, K. S.; Yip, H. L.; Sun, Y.; Davies, J. A.; Chen, F. C.; Jen, A. K. Y. Chem. Commun. 2011, 47, 1102611028.

(32) Lee, D. Y.; Stone, S. W.; Ferraris, J. P. Chem. Commun. 2011, 47, 10987-10989.

(33) Li, Z.; Lu, J. P.; Tse, S. C.; Zhou, J. Y.; Du, X. M.; Tao, Y.; Ding, J. F. J. Mater. Chem. 2011, 21, 3226-3233.

(34) Huang, Y.; Liu, F.; Guo, X.; Zhang, W.; Gu, Y.; Zhang, J. P.; Han, C. C.; Russell, T. P.; Hou, J. H. Adv. Energy Mater. 2013, 3, 930937.

(35) Hou, Q.; Zhou, Q. M.; Zhang, Y.; Yang, W.; Yang, R. Q.; Cao, Y. Macromolecules 2004, 37, 6299-6305.

(36) Mei, C. Y.; Liang, L.; Zhao, F. G.; Wang, J. T.; Yu, L. F.; Li, Y. X.; Li, W. S. Macromolecules 2013, 46, 7920-7931.

(37) Frisch, M. J.; Trucks, G. W.; Schlegel, H. B.; Scuseria, G. E.; Robb, M. A.; Cheeseman, J. R.; Scalmani, G.; Barone, V.; Mennucci, B.; Petersson, G. A.; Nakatsuji, H.; Caricato, M.; Li, X.; Hratchian, H. P.; Izmaylov, A. F.; Bloino, J.; Zheng, G.; Sonnenberg, J. L.; Hada, M.; Ehara, M.; Toyota, K.; Fukuda, R.; Hasegawa, J.; Ishida, M.; Nakajima, T.; Honda, Y.; Kitao, O.; Nakai, H.; Vreven, T.; Montgomery, J. A.; Peralta, J. E.; Ogliaro, F.; Bearpark, M.; Heyd, J. J.; Brothers, E.; Kudin, K. N.; Staroverov, V. N.; Kobayashi, R.; Normand, J.; Raghavachari, K.; Rendell, A.; Burant, J. C.; Iyengar, S. S.; Tomasi, J.; Cossi, M.; Rega, N.; Millam, J. M.; Klene, M.; Knox, J. E.; Cross, J. B.; Bakken, V.; Adamo, C.; Jaramillo, J.; Gomperts, R.; Stratmann, R. E.; Yazyev, O.; Austin, A. J.; Cammi, R.; Pomelli, C.; Ochterski, J. W.; Martin, R. L.; Morokuma, K.; Zakrzewski, V. G.; Voth, G. A.; Salvador, P.; Dannenberg, J. J.; Dapprich, S.; Daniels, A. D.; Farkas, Ö.; Foresman, J. B.; Ortiz, J. V.; Cioslowski, J.; Fox, D. J. Gaussian 09, Revision A.1, Gaussian, Inc.: Wallingford, CT, 2009.

(38) Beaujuge, P. M.; Amb, C. M.; Reynolds, J. R. Acc. Chem. Res. 2010, 43, 1396-1407.

(39) Zhou, H. X.; Yang, L. Q.; Xiao, S. Q.; Liu, S. B.; You, W. Macromolecules 2009, 43, 811-820.

(40) Andersson, M. R.; Thomas, O.; Mammo, W.; Svensson, M.; Theander, M.; Inganäs, O. J. Mater. Chem. 1999, 9, 1933-1940.

(41) Wang, H. J.; Chou, C. W.; Chen, C. P.; Chen, Y. H.; Lee, R. H.; Jeng, R. J. J. Mater. Chem. A 2013, 1, 8950-8960.

(42) Zhou, H. X.; Yang, L. Q.; Stoneking, S.; You, W. ACS Appl. Mater. Interfaces 2010, 2, 1377-1383.

(43) Han, L. L.; Bao, X. C.; Hu, T.; Du, Z. K.; Chen, W. C.; Zhu, D. Q.; Liu, Q.; Sun, M. L.; Yang, R. Q. Macromol. Rapid Commun. 2014, $35,1153-1157$.

(44) Wang, N.; Chen, Z.; Wei, W.; Jiang, Z. H. J. Am. Chem. Soc. 2013, 135, 17060-17068.

(45) Peet, J.; Kim, J. Y.; Coates, N. E.; Ma, W. L.; Moses, D.; Heeger, A. J.; Bazan, G. C. Nat. Mater. 2007, 6, 497-500. 
(46) Lee, J. K.; Ma, W. L.; Brabec, C. J.; Yuen, J.; Moon, J. S.; Kim, J. Y.; Lee, K. H.; Bazan, G. C.; Heeger, A. J. J. Am. Chem. Soc. 2008, 130, 3619-3623.

(47) Park, S. H.; Roy, A.; Beaupre, S.; Cho, S.; Coates, N.; Moon, J. S.; Moses, D.; Leclerc, M.; Lee, K. H.; Heeger, A. J. Nat. Photonics 2009, 3, 297-302.

(48) Li, W. W.; Hendriks, K. H.; Furlan, A.; Roelofs, W. S. C.; Meskers, S. C. J.; Wienk, M. M.; Janssen, R. A. J. Adv. Mater. 2014, 26, $1565-1570$.

(49) Shaw, P. E.; Ruseckas, A.; Samuel, I. D. W. Adv. Mater. 2008, 20, 3516-3520.

(50) Li, W. W.; Hendriks, K. H.; Furlan, A.; Roelofs, W. S. C.; Wienk, M. M.; Janssen, R. A. J. J. Am. Chem. Soc. 2013, 135, 18942-18948.

(51) Price, S. C.; Stuart, A. C.; Yang, L. Q.; Zhou, H. X.; You, W. J. Am. Chem. Soc. 2011, 133, 4625-4631.

(52) Min, J.; Zhang, Z. G.; Zhang, S. Y.; Li, Y. F. Chem. Mater. 2012, $24,3247-3254$. 